\title{
Shanu N. Kothari, MD, FACS, FASMBS
}

\author{
Shanu N. Kothari ${ }^{1}$
}

Published online: 26 March 2021

(C) The Author(s), under exclusive licence to Springer Science+Business Media, LLC, part of Springer Nature 2021

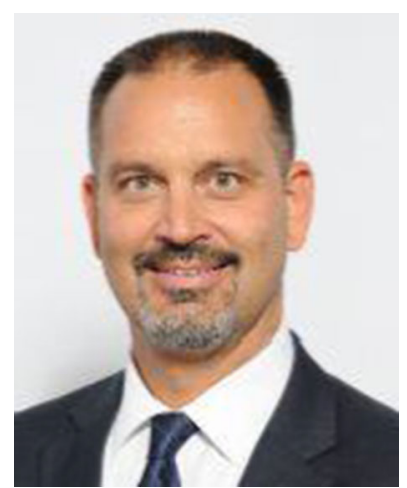

Shanu N. Kothari, MD, has dedicated much of his surgical career to caring for patients with obesity, leading initiatives to improve the care for patients with obesity, and researching obesity-related issues. Dr. Kothari has influenced the field of bariatric and metabolic surgery, minimally invasive foregut and general surgery through education, mentorship, leadership, and service.

Dr. Kothari earned his Bachelor of Arts degree in Biology from Anderson University in Anderson, Indiana, and his Medical Degree from the University of Illinois College of Medicine-Peoria in Peoria, Illinois. He completed his general surgery residency at Gundersen Lutheran Medical Foundation in La Crosse, Wisconsin, and his fellowship in Minimally Invasive Surgery at Virginia Commonwealth University in Richmond, Virginia. He is the current Vice Chair of Medical Staff Affairs at Prisma Health in Greenville, South Carolina.

Dr. Kothari established an accredited, comprehensive minimally invasive bariatric surgery program at Gundersen Health System, a community-based training program in La Crosse, Wisconsin, and served as its Director from 2001 to

Shanu N. Kothari

shanu.kothari@prismahealth.org

1 Prisma Health, Department of Surgery, Greenville, SC 29601, USA
2019. He also established a Minimally Invasive Bariatric Surgery and Advanced Laparoscopy Fellowship through the Gundersen Lutheran Medical Foundation in 2003 and served as the fellowship director from 2003 to 2019 , having mentored and trained 16 fellowship graduates, three of whom joined his surgical practice. He has also mentored ten undergraduate students in medical research fellowships. He has established an endowed scholarship at Anderson University for undergraduate students pursuing a medical career. He previously held an appointment as adjunct Faculty at the University of Wisconsin School of Medicine and Public Health and is currently Associate Professor at the University of South Carolina School of Medicine in Greenville, South Carolina.

Dr. Kothari has a strong interest in the study of leadership and was awarded a Brandeis Scholarship in 2018. He is the current President-Elect of the American Society for Metabolic and Bariatric Surgery (ASMBS), President-Elect of the Southwestern Surgical Congress, and Second Vice President of the Fellowship Council. He is the past President of the Wisconsin Surgical Society - a chapter of the American College of Surgeons, Past Chair of the ASMBS Clinical Issues Committee and Program Committee, past Co-Chair of the 2015 Obesity Summit, and has previously served as a member of the ASMBS Revisional Surgery and National Quality Forum Taskforces, ASMBS Quality Improvement Committee, and ASMBS Task Force: Integrating Emerging Technology \& Procedures into Clinical Practice. He has also served as a Fellowship Council Executive Committee Member At-Large. He is currently a member of the ASMBS Executive Council, Advocacy Committee, and State Access to Care Representative (STAR) for the upper Midwest region, Flexible Endoscopy Committee, ASMBS Rural Surgery Committee. He served as a mentor for two ASMBS quality improvement initiatives, ENERGY (Enhanced Recovery Goals in Bariatric Surgery) and DROP (Decreasing Readmissions through Opportunities Provided). Dr. Kothari has worked to foster several collaborative efforts with other national medical societies including the National Lipid Society, American Association of Hip and Knee Surgeons, and the American College of Obstetricians and Gynecologists. 
As a community surgeon, Dr. Kothari takes pride in training residents and fellows who practice in rural and underserved areas. His research and scholarly accolades include over 150 presentations at regional, national, and international conferences and over 130 publications, including 18 book chapters. He served as the senior editor of a 2011 Surgical Clinics of North America issue dedicated to Metabolic and Bariatric surgery and will reassume the editor role again in a 2021 issue. He is an editor of Obesity Care and Bariatric Surgery and associate editor of Evidence-Based Approach to Minimally Invasive Surgery and an Associate Editor for Surgery for Obesity and Related Diseases. Dr. Kothari served as the senior author for the ASMBS 2015 and 2014 Top Video Award presentations, the 2010 ASMBS Karl Storz Endoscopy America Fellow Scholarship Award, and the
2017 John Halvorson Young Investigator award presentation as well as three ASMBS ObesityWeek Top Ten papers.

Dr. Kothari has participated in multiple medical mission trips to Haiti with Mountain Top Ministries and Project Haiti and has delivered virtual lectures to trainees in Haiti. He and his family have been involved members of their local church in Wisconsin where he led a weekly bible study for 17 years. Dr. Kothari is an avid boater, having circumnavigated Lake Michigan in 2011 with his family and dog, an experience which offered many parallels to life as a surgeon.

Publisher's Note Springer Nature remains neutral with regard to jurisdictional claims in published maps and institutional affiliations. 